Positive childhood experiences and trauma in adulthood: Psychometric properties of the Benevolent Childhood Experiences Scale (BCEs) among the Portuguese population Telma Catarina Almeida ${ }^{\mathrm{a} *}$, Renata Guarda ${ }^{\mathrm{b}}, \& \mathrm{Olga} \mathrm{Cunha}^{\mathrm{c}}$

[a] LabPSI - Laboratório de Psicologia Egas Moniz, Instituto Universitário Egas Moniz, Caparica, Portugal; CiiEM - Centro de Investigação Interdisciplinar Egas Moniz, Instituto Universitário Egas Moniz, Caparica, Portugal; ORCID: 0000-0002-3354-7809

[b] LabPSI - Laboratório de Psicologia Egas Moniz, Instituto Universitário Egas Moniz, Caparica, Portugal; ORCID: 0000-0002-9168-1651

[c] Faculdade de Psicologia, Educação e Desporto, Universidade Lusófona do Porto, Portugal; ORCID: 0000-0001-9747-2343

* Corresponding author: Telma C. Almeida, LabPSI - Laboratório de Psicologia Egas Moniz, CiiEM - Centro de Investigação Interdisciplinar Egas Moniz, Instituto Universitário Egas Moniz, Campus Universitário, Quinta da Granja, Monte de Caparica, 2829 - 511 Caparica. Phone: (+351) 212946 700. Email: talmeida@egasmoniz.edu.pt

This manuscript was accepted for publication in Child Abuse and Neglect. 


\title{
Positive childhood experiences and trauma in adulthood: Psychometric properties of the Benevolent Childhood Experiences Scale (BCEs) among the Portuguese population
}

\begin{abstract}
Background: Positive childhood experiences have a positive effect on adulthood, and the absence of positive experiences can be more damaging throughout life than the presence of trauma. Recently, researchers have developed the Benevolent Childhood Experiences Scale (BCEs), an instrument designed to assess positive childhood experiences. Objectives: The present study aims to adapt the BCEs to the Portuguese population and examine its psychometric properties. Participants: 1,886 adults with a mean age of 36.36 years $(S D=$ 13.66) participated in this study. Methods: Participants responded to an online protocol consisting of a sociodemographic questionnaire, the BCEs, and the Childhood Trauma Questionnaire (CTQ). Results: Exploratory and confirmatory factor analysis results revealed a one-factor structure for the BCEs with a good fit. Results also indicated satisfactory internal consistency and discriminant validity values. Predictive validity showed that higher BCEs scores predicted fewer trauma and victimization experiences in the last three years, but only before accounting for adverse childhood experiences. Conclusions: Overall, the results support the assertion that the Portuguese version of the BCEs is a valuable, brief, and psychometrically reliable instrument to measure positive life experiences that is suitable for use in Portugal.
\end{abstract}

Keywords: childhood; benevolent experiences; trauma; adulthood; victimization

Funding: This work is financed by national funds through the FCT - Foundation for Science and Technology, I.P., under the project UIDB/04585/2020. 


\section{Introduction}

For many years, psychology has strongly emphasized dysfunction and psychopathology (Gable \& Haidt, 2005). For this reason, the relationship between negative life experiences and negative outcomes is well documented. Several studies have confirmed some of these negative experiences' effects, such as emotional maladjustment, victimization experiences (Merrick, Narayan, Atzl, \& Harris, 2020), antisocial behaviors (Braga, Cunha, \& Maia, 2018), and mental disorders (Gunay-Oge, Pehlivan, \& Isikli, 2020). However, positive life experiences tend to occur more frequently than negative ones (Gable \& Haidt, 2005).

Psychological trauma can occur at any point in life, often differing in its intensity and severity (Eizirik et al., 2006). Furthermore, not all individuals experience traumatic events in the same way (Peres, Merchant, \& Nasello, 2005). Childhood trauma victimization is usually associated with child maltreatment, such as emotional abuse, physical abuse, sexual abuse, emotional neglect, and physical neglect. Trauma can be derived from both first-person experiences or by simply witnessing traumatic events (Beilharz et al., 2019), may occur during childhood or adolescence, and may have negative repercussions on adults' mental health (Bussey \& Wise, 2007). Adverse childhood experiences negatively influence intelligence coefficient, academic achievement, and cognitive, emotional, and executive functioning (Nikulina \& Widom, 2013). Childhood trauma is also associated with various health problems in adulthood, such as anxiety, obsessive-compulsive disorders, suicidal thoughts, and depression (Assche, Ven, Vandenbulcke, \& Luyten, 2020; Mersky, 2013). Increased suffering, reactivity, and a lack of sleep are also linked to childhood trauma (Beilharz et al., 2019), in addition to low psychosocial abilities in adulthood, especially when children experience emotional abuse, emotional neglect, and physical neglect (Beilharz et al., 2019). A metaanalysis demonstrated that child abuse is related to antisocial behavior in adulthood, especially when abuse occurs in childhood and adolescence (Braga et al., 2018). Trauma victimization 
experiences can be difficult to process throughout life, leading to a range of emotions, encompassing anger, sadness, confusion, and hopelessness (Beilharz et al., 2019).

Prior research has been particularly concerned with understanding how positive childhood experiences may mediate the impact of childhood trauma, conferring resilience in adverse contexts (Merrick, Narayan, DePasquale, \& Masten, 2019; Narayan, Rivera, Bernstein, Harris, \& Lieberman, 2018). The literature indicates that positive childhood experiences, including healthy attachment bonds, effective parenting behaviors, and other community resources, influence long-term development and have positive effects in adulthood, in addition to showing that an absence of positive childhood experiences can be more harmful throughout life than the presence of trauma (Crandall et al., 2019; Wright, Masten, \& Narayan, 2013). Positive life experiences are not equivalent to the opposite or the absence of problematic behaviors but imply the development of social skills (Kosterman et al., 2005; Kosterman et al., 2011). Bethell et al. (2019) also concluded that positive childhood experiences are associated with social and relational skills, as well as good health, among adults. For example, safe childhood attachment and effective parenting behaviors (Cicchetti \& Toth, 2009; Wright et al., 2013) can provide protective effects related to young people's social and emotional skills (Yamaoka \& Bard, 2019). Furthermore, quality relationships with colleagues, teachers, and family (Cicchetti, 2009; Park, 2004) and self-recognition (Cicchetti \& Toth, 2009) form a part of positive experiences. All of these positive experiences occur in individuals' daily lives through their interactions with their physical and social worlds (Park, 2004). They can also help children adapt to other events, including negative experiences, such as abuse and exposure to violence (Luther, 2015). These positive experiences are crucial quality of life factors, in addition to being associated with positive development (Park, 2004) and good health (Bethell, Jones, Gombojav, Linkenbach, \& Sege, 2019). Positive experiences and strong childhood relationships enhance resilience building, helping individuals to better endure adverse 
experiences throughout life (Poole, Dobson, \& Pusch 2017; Sege \& Browne, 2017). It is necessary to take into account youth characteristics, parental lifestyles, socioeconomic status, and adverse life events (Caldera \& Hart, 2004), since childhood experiences can play a positive role in adult life functioning (Narayan et al., 2018) and counteract the long-term effects of childhood adversity (Gunay-Oge, Pehlivan, \& Isiki, 2020; Karatzias et al., 2020)

According to the developmental psychopathology theory (Cicchetti \& Toth, 2005; Toth \& Cicchetti, 2013), early positive life experiences and secure relationships provide the necessary safety for individuals to acquire developmental abilities (e.g., resilience, self-control, emotional regulation, empathy, etc.), protecting them against involvement in maladjustment trajectories and developing mental health problems. Thus, social experiences early on in life, such as bonding with caregivers and forming quality relationships with family members, peers, and teachers are a key factor behind healthy future relationships and the integration of social experiences (Cicchetti \& Toth, 2009). In contrast, adverse experiences deprive children of the expectable environment crucial to their development, leaving them more vulnerable to risk factors (e.g., interpersonal, cognitive, emotional, biological, etc.) that can contribute to antisocial behavior (Toth \& Cicchetti, 2013). Positive self and relational experiences are essential to developing buffering effects against early adversity (Luthar, Crossman, \& Small, 2015) and contributing to resilient functioning (Masten \& Cicchetti, 2016; Poole, Dobson, \& Pusch, 2017). Empirical evidence supports the idea that positive childhood experiences can act as promotive factors for positive adulthood functioning (Hillis et al., 2010).

\section{The Benevolent Childhood Experiences Scale (BCEs)}

The Benevolent Childhood Experiences Scale (BCEs: Narayan et al., 2018) was created to bridge the gaps present in other instruments that also seek to assess positive life experiences. The BCEs is a culturally sensitive instrument that is suitable for use in both rural and urban 
areas and in more developed and less developed regions, among all socioeconomic groups (Narayan et al., 2018). This scale assesses the presence of 10 favorable childhood experiences, using a Yes/No response format, and yields a total score out of 10. The authors divided positive childhood experiences into three categories, encompassing perceived relational and internal security (e.g., there was at least one safe caregiver and beliefs that provided comfort), positive and predictable quality of life (e.g., regular meals and a bedtime), and interpersonal support (e.g., a caring teacher). The scale's dichotomous response format makes the instrument more objective and provides adequate reliability, discarding events details, such as frequency, that could make the instrument less reliable (Narayan et al., 2018). Since the BCEs consists of few items, it also allows for a quick response time. Narayan et al. (2018) tested the scale's psychometric properties among a sample of ethnically diverse, low-income, pregnant women with high levels of childhood adversity. Among this sample, the instrument revealed promising psychometric properties with an excellent test-retest reliability $(r=.80, p<.001$; Narayan et al., 2018). In that study, higher BCEs scores among participants 0 to 18 years old predicted lower levels of prenatal post-traumatic stress disorder (PTSD) symptoms and exposure to stressful prenatal life events, after accounting for the effects of adverse childhood experiences. In a later study that aimed to examine the psychometric properties of the BCEs in a sample of homeless parents, Merrick et al. (2019) concluded that higher BCEs scores predicted a lower probability of psychological distress, signifying the scale's promise as a brief measurement instrument linking positive childhood experiences to better long-term functioning among highrisk populations.

Other study has also adapted the BCEs into Turkish, in addition to investigating its psychometric properties (Gunay-Oge, Pehlivan, \& Isikli, 2020). Gunay-Oge et al.'s (2020) study applied the BCEs to two samples, including a sample of university psychology students and an online sample. Through an exploratory factor analysis (EFA) and a confirmatory factor 
analysis (CFA), these authors uncovered two factors that comprise the scale, encompassing perceived safety and support and internal and environmental motivation. The 10-item scale demonstrated satisfactory reliability values, and its internal consistency coefficient was equal to .61 for the total score and to .55 and .45 for the perceived safety and support scale and the internal and environmental motivation scale, respectively (Gunay-Oge et al., 2020). Furthermore, the test-retest validity coefficient was .91. As a result, Gunay-Oge et al. (2020) concluded that the Turkish version of the BCEs could be used as a valid and reliable tool among the Turkish population and that it possessed psychometric properties similar to the original English version.

The need to adapt the BCEs to the Portuguese population is based on the scarcity of measurement instruments that assess positive childhood experiences among this population. To the best of our knowledge, there are at least two instruments that assess positive childhood/adolescent experiences in the Portuguese context, namely the Lifetime Experiences Scale (LIFES; Azevedo, 2016) and the Positive Experiences Questionnaire (Marques-Pinto et al., 2019). However, the BCEs' characteristics (i.e., culturally sensitive, brief, quick response time, objective, etc.) make it a promising tool. Thus, this study aimed to translate and adapt the recently developed BCEs to the Portuguese context and to test its adequacy for use in Portugal, by examining its psychometric properties.

\section{Methods}

\section{Sample}

A total of 1,886 individuals between the ages of 18 and 91 years old $(M=36.36, S D=$ 13.66) participated in this study, among whom $1,475(78.2 \%)$ were women and $411(21.8 \%)$ were men. 884 (46.9\%) participants were single, 842 (44.6\%) were married or lived with their partner, $145(7.7 \%)$ were separated or divorced, and $15(.8 \%)$ were widowed. 
Concerning participants' educational attainment, 93 (4.9\%) participants had attended school up to the 9th grade, $577(30.6 \%)$ had attended school up to or completed the 12th grade, and $1,107(58.7 \%)$ possessed a bachelor's degree or higher. $788(41.8 \%)$ participants reported having suffered some type of trauma in the past three years, while $372(19.7 \%)$ claimed to have suffered some type of victimization in the last three years.

\section{Measures}

Sociodemographic questionnaire. A sociodemographic questionnaire was developed to gather information about participants' age, gender, educational attainment, professional status, and marital status. The questionnaire asked participants "Have you suffered some type of trauma in the last three years (persecution, divorce, physical assault, sexual assault, theft/assault, housing damage from natural disasters, serious injury, spontaneous abortion, or any other type of trauma)?" The researchers constructed the victimization analysis by evaluating the traumas reported in response to the previous question.

The Benevolent Childhood Experiences Scale (BCEs: Narayan et al., 2018). This scale was created to evaluate the presence of people's positive experiences and resources that occurred when they were between 0 and 18 years old. It is composed of 10 items that must be answered using a Yes/No dichotomous response format, and it aims to identify relational and internal safety and security, positive and predictable quality of life, and interpersonal support.

The Childhood Trauma Questionnaire (CTQ; Bernstein et al., 2003; CTQ Portuguese version; Dias, Sales, Carvalho, Castro-Vale, Kleber, \& Cardoso, 2013). The CTQ was developed to assess the existence of traumatic abuse experiences during childhood. The instrument consists of 28 items, answered using a 5-point Likert scale ('Never true', 'Rarely true', 'Sometimes true', 'Often true', and 'Very often true'). The CTQ is composed of five subscales representing different types of maltreatment, encompassing emotional abuse, 
physical abuse, sexual abuse, physical neglect, and emotional neglect. The original version shows good psychometric properties, indicating internal consistency values of .89 for emotional abuse, .82 for physical abuse, .92 for sexual abuse, .66 for physical neglect, and .89 for emotional neglect (Bernstein et al., 2003). The Portuguese version of the CTQ (Dias et al., 2013) possessed Cronbach's alphas of .84 for the total scale, .71 for emotional abuse, .77 for physical abuse, .71 for sexual abuse, .47 for physical neglect, and .79 for emotional neglect, respectively. For the current study sample, the internal consistency values were .77 for the total score, .83 for emotional abuse, .87 for emotional neglect, .84 for sexual abuse, .83 for physical abuse, and .50 for physical neglect.

\section{Procedure}

This study utilized a cross-sectional design with a non-probabilistic sample. First, three researchers translated the BCEs from English to Portuguese, and, subsequently, two researchers translated it from Portuguese to English. The final version of the BCEs, the CTQ, and the sociodemographic questionnaire were uploaded to Google Forms. The link to fill out the research protocol was disseminated through social networks and email. Information on the study objectives and procedures was included on the first page of the protocol, which also stated that participants' responses would be anonymous and confidential. Additionally, all participants electronically signed an informed consent waiver. The researchers conducted this study in accordance with the ethical principles outlined in the Declaration of Helsinki (World Medical Association, 2013), and the research protocol was approved by the Institutional Review Board of the researchers' university.

\section{Data Analysis}

First, descriptive statistics for the total BCEs score and all BCEs items were calculated. Next, the construct validity of the scale was tested using an exploratory factor analysis (EFA). 
The factorial structure established by EFA was then tested through a confirmatory factor analysis (CFA). To assess the adjustment quality of the model, the following indexes were used: a) the Compared Fit Index (CFI), the Non-Normed Fit Index (NFI), and the Goodness of Fit Index (GFI), higher than .90.; b) the Root Mean Square of Approximation (RMSEA; 90\% Confidence Interval) lower than .05 (Marôco, 2014). The study evaluated reliability using Cronbach's alphas ( $\geq .70$; cf. Hair et al., 1998) and mean inter-item correlations (values ranging from .15 to .50; cf. Domino \& Domino, 2006). In addition, discriminant validity was assessed by testing the correlation coefficient among the total BCEs score and the total CTQ score and subscales. A one-way ANOVA was utilized to test the total BCEs score, while the BCEs' predictive validity was assessed through four binary logistic regressions, to identify the predictors of trauma in the last three years and the predictors of victimization experiences in the last three years. At least, a hierarchical cluster analysis using Ward's method was used to examined whether subgroups of participants differed in the mean levels of BCEs and CTQ. The dendrogram for the overall solution was analyzed to estimate the number of clusters. Subsequently, differences tests were performed to examine whether sociodemographic variables, the incidence of trauma in the last three years, and the incidence of victimization experiences in the last three years differed among cluster groups.

Statistical Package for Social Sciences (SPSS; IBM SPSS Statistics. Version 26.0), and the Analysis of Moment Structures (AMOS; Version 25.0) were used to perform the analyzes.

\section{Results}

\section{Descriptive Analysis}

Concerning the total BCEs score (see Table 1), participants presented considerably high levels of positive childhood experiences $(M=8.92, S D=1.55)$. The most prevalent positive experiences reported were having at least one caregiver with whom they felt safe $(96.5 \%)$, 
having at least one good friend $(96.8 \%)$, having at least one teacher who cared about them (92.2\%), and having opportunities to have a good time (94.4\%).

\section{Insert Table 1 here}

\section{Construct Validity}

As the BCEs' factor structure had not been investigated in the process of developing the original instrument, an exploratory factor analysis (EFA) was carried out to test BCEs' construct validity. Before performing EFA, the adequacy of the data for factor analysis was assessed through Bartlett test and Kaiser-Meyer-Olkin (KMO) measure. For data to be considered adequate for factor analysis, the Bartlett test results must be statistically significant, and the KMO is expected to be above .50 . The Bartlett test and the KMO results showed that our data is adequate for analysis $\left(\mathrm{KMO}=.813\right.$; Bartlett's test, $\left.\square^{2}(45)=1922.676, p<.001\right)$. To examine the factor structure of the scale and determine subdimensions, factor analysis was performed using different rotations (varimax, quartimax, equamax, and direct oblimin). None of the EFA produced interpretable factor structures; thus, the instrument appears to be most suited to a one-dimensional structure.

The one-dimensional structure was then tested utilizing CFA. The CFA showed that this model possessed an adequate fit index $\left(\square^{2}(34)=152.731, p<.001 ; \square^{2} / \mathrm{df}=4.49\right.$; GFI $=$ $.99 ; \mathrm{CFI}=.94 ; \mathrm{NFI}=.92 ; \mathrm{RMSEA}=.043[.036, .050])$, with all relevant indices confirming the BCEs' acceptable factor structure.

\section{Internal Consistency}

Internal consistency reliability was measured by calculating Cronbach's alpha coefficient. The analysis found a reliability coefficient of .68 for the total BCEs score. Based on average inter-item correlations, the total BCEs score showed good internal consistency $(\mathrm{AIIC}=.19)$, within the recommended value range of .15-.50 (Domino \& Domino, 2006). 


\section{Discriminant Validity}

To study the association between benevolent experiences in childhood (BCEs) and childhood trauma (CTQ), Pearson's correlation test was performed. The results showed statistically significant negative associations between the total BCEs score and the total CTQ score and subscales (see Table 2).

\section{Insert Table 2 here}

To examine differences in the BCEs scores among different groups and variables (e.g., age, marital status, educational qualifications, professional status, a trauma in the last three years, and victimization in the last three years) the One-Way ANOVA was used. These results are presented in Table 3. Regarding age, two groups were defined (18 years old to 40, and over 40 years). Participants with 41 or more years of age had higher scores on the total score of BCE, $F(1,18)=4.10, p=.043$ (Table 3$)$. There were also statistically significant total BCEs score differences among marital status groups, $F(3,18)=3.95, p<.001$, with Tukey post-hoc tests showing that married participants had a higher average BCEs score when compared to single participants.

Concerning educational attainment, there were statistically significant differences among groups' total BCEs scores, $F(2,11)=13.18, p<.001$. Tukey post-hoc tests showed that participants with a complete university education had higher total BCEs scores, in comparison with those who had completed the 9th and 12th grade, respectively. Additionally, participants with a complete $12^{\text {th }}$ grade education also demonstrated higher average total BCEs scores than those who had finished the $9^{\text {th }}$ grade.

An analysis of participants' professional status found statistically significant differences among groups' total BCEs scores, $F(4,18)=7.21, p<.001$. The Tukey test showed that employed, retired, and student participants had higher scores than unemployed participants. Furthermore, employed individuals also possessed higher scores than students. 
There were statistically significant differences among the groups regarding the incidence of traumatic experiences over the last three years, $F(1,18)=38.33, p<.001$. Participants who had not suffered trauma had higher total scale scores. Concerning the occurrence of victimization experiences during the last three years, the results showed statistically significant differences among the groups, $F(1,18)=47.53, p<.001$, with the group that had not suffered victimization possessing one of the highest scores.

\section{Insert Table 3 here}

\section{Predictive Validity}

Four binary logistic regressions were performed to identify the predictors of trauma in the last three years and the predictors of experiences of victimization in the last three years. The total BCEs and CTQ scores (Models 1 and 2; Table 4) and the total BCEs scores and CTQ subscale scores (Models 3 and 4; Table 5) were utilized as predictors in four independent models after controlling for age, gender, professional status, marital status, and educational attainment.

In the models predicting trauma experiences in the last three years, the variables included in the first step resulted in a statistically significant model, $\square^{2}(11)=21.96, p=.02$. These variables produced a pseudo- $R 2$ between $1.3 \%$ (Cox \& Snell) and 1.8\% (Nagelkerke), indicating that the model accurately classified $61.1 \%$ of cases. However, none of the variables were related to the incidence of traumatic experiences over the last three years. Following the addition of the total BCEs (Model 1, Step 2) scale to this analysis, the model was also statistically significant, $\square 2(1)=22.46, p<.001$. The contribution of these variables produced a pseudo- $R 2$ between $2.7 \%$ (Cox \& Snell) and 3.6\% (Nagelkerke), indicating that the model accurately classified $62.8 \%$ of cases. The total BCEs score is negatively related to the incidence of traumatic experiences in the last three years $(\mathrm{OR}=.205)$. The addition of the total CTQ (Model 1, Step 3) yielded a statistically significant model, $\square^{2}(1)=29.75, p<.001$, while the 
global model was also statistically significant, $\square^{2}(13)=74.18, p<.001$. The contribution of this variable produced a pseudo- $R 2$ between $4.4 \%$ (Cox \& Snell) and 6\% (Nagelkerke), accurately classifying $63.7 \%$ of cases. A separate analysis of the variables used to predict traumatic experiences revealed that only the total CTQ score $(\mathrm{OR}=2.93)$ was positively related to the incidence of traumatic experiences over the last three years (Table 4).

\section{Insert Table 4 here}

Following the inclusion of the CTQ subscales in the analysis (Model 3, Step 3), the model was also statistically significant, $\square^{2}(5)=43.75, p<.001$, as was the global model, $\square^{2}(17)=88.17, p<.001$. The contribution of this variable produced a pseudo- $R 2$ between $5.2 \%$ (Cox \& Snell) and 7.1\% (Nagelkerke), accurately classifying $64.6 \%$ of cases. An individual analysis of the variables revealed that being separated or divorced $(\mathrm{OR}=1.49)$, the CTQ emotional abuse subscale $(\mathrm{OR}=1.09)$, and the CTQ physical neglect subscale $(\mathrm{OR}=$ 1.05) are positively related to the occurrence of traumatic experiences in the last three years (Table 5).

In the models predicting victimization experiences over the last three years, the variables included in the first step produced a statistically significant model, $\square^{2}(11)=61.07, p$ $<.001$. These variables yielded a pseudo- $R 2$ between $3.7 \%$ (Cox \& Snell) and $5.9 \%$ (Nagelkerke), indicating that the model accurately classified $81 \%$ of cases. Age [OR $=.978$ ] and being unemployed $[\mathrm{OR}=.377]$ were negatively correlated with the incidence of victimization experiences during the last three years. When the total BCEs (Model 2, Step 2) is added to this analysis, the new model is also statistically significant, $\square^{2}(1)=25.08, p<.001$. The contribution of these variables produced a pseudo- $R 2$ between $5.1 \%$ (Cox \& Snell) and $8.2 \%$ (Nagelkerke), indicating that this model accurately classified $80.9 \%$ of cases. An analysis of this model revealed that age $[\mathrm{OR}=.978]$ and the total $\mathrm{BCEs}$ score $[\mathrm{OR}=.142]$ were negatively associated with victimization experiences in the last three years. When the total 
CTQ was included in the analysis (Model 2, Step 3), the model was also significant, $\square^{2}(1)=$ 25.92, $p<.001$, as was the global model, $\square^{2}(13)=112.07, p<.001$, producing a pseudo- $R 2$ between $6.6 \%$ (Cox \& Snell) and 10.6\% (Nagelkerke) and correctly classifying $81.4 \%$ of cases. Age $(\mathrm{OR}=.97)$ is negatively related to victimization experiences in the last three years, while total CTQ scores $(\mathrm{OR}=3.14)$ are positively related (Table 4).

The model that includes the CTQ subscales (Model 4, Step 3), $\square^{2}(5)=40.13, p<.001$, as well as the global model, $\left(\square^{2}(17)=126.28, p<.001\right.$, are both significant. These variables produced a Pseudo-R2 that varies between 7.4\% (Cox \& Snell) and 11.9\% (Nagelkerke), accurately classifying $81.4 \%$ of cases. An individual variable analysis showed that age $(\mathrm{OR}=$ .97 ) is negatively related to the occurrence of victimization experiences in the last three years, while the CTQ emotional abuse subscale $(\mathrm{OR}=1.10)$ is positively related (Table 5).

\section{Insert Table 5 here}

\section{Cluster Analysis of the BCEs and the CTQ}

The results of the cluster analysis indicated a three-cluster solution (Table 6). This solution identifies three groups, encompassing those with low BCEs and high maltreatment levels (Cluster 1 - "Low BCEs", $n=108$ ), those with high BCEs and low maltreatment levels (Cluster 2 - "High BCEs", $n=1,308$ ), and those with moderate BCEs and moderate maltreatment levels (Cluster 3 - "Moderate BCEs", $n=470$ ).

Chi-squared tests revealed significant differences among clusters for marital status, professional status, traumatic experiences in the last three years, and victimization experiences in the last three years (see Table 6). The Low BCEs cluster included significantly more separated or divorced and unemployed individuals and demonstrated significantly higher levels of trauma and victimization in the last three years, compared to the High BCEs and the Moderate BCEs clusters. A Kruskal-Wallis test showed statistically significant differences 
among clusters based on educational attainment. Mann-Whitney post-hoc tests indicated that the Low BCEs cluster had significantly lower educational levels than the High BCEs cluster, $U=50769.000, p=.001$, and that the High BCEs cluster had significantly higher educational levels than the Moderate BCEs cluster, $U=249928.00, p=.00$.

\section{Insert Table 6 here}

\section{Discussion}

This study's main objective was to adapt the recently developed BCEs to Portuguese and to test its adequacy for use among the Portuguese population, in addition to examining its psychometric properties. The study's findings showed that the BCEs possessed appropriate psychometric properties, and that it was a valid and reliable tool for use in the Portuguese context.

Positive childhood experiences were common among participants, with the most prevalent positive experiences reported being having at least one caregiver with whom they felt safe, having at least one good friend, having at least one teacher who cared about them, and having opportunities to have fun. These results are in accordance with previous studies that have also used the BCEs (e.g., Karatzias et al., 2020; Merrick et al., 2019; Narayan et al., 2018). Moreover, most studies have reported that positive childhood experiences are associated with bonding with caregivers (Wright et al., 2013) and good relationships with peers and teachers (Cicchetti \& Toth, 2009)

Exploratory factor analysis was used to test the BCEs' factorial structure since the original authors did not test it through statistical analysis, and instead, theoretically organized the BCEs' items in three scales, encompassing perceived internal and external safety, positive and predictable quality of life, and relational support. The EFA findings revealed that the analysis did not produce an interpretable factorial structure, leading the researchers to conclude 
that a one-dimensional structure is the most suitable for the BCEs scale. A confirmatory factor analysis supported the BCEs' one-dimensional structure, revealing a good model fit. These findings diverge from those of Gunay-Oge et al. (2020), who found a two-factor structure for the instrument.

Regarding the BCEs' internal consistency, the scale possessed acceptable Cronbach's alphas ( $\alpha=.68$; Taber, 2018), although they were lower than .70. Furthermore, the Cronbach's alphas were consistent with those found by Gunay-Oge et al. (2020). However, these results are in accordance with Cronbach's (1951) definition of alpha, which concluded that a smaller number of items would lead to a lower alpha value (Field, 2017). Thus, since the BCEs consists of only 10 items, it is more likely to demonstrate a lower Cronbach's alpha (Vet, Mokkink, Mosmuller, \& Terwee, 2017). As Cronbach's alpha is sensitive to the number of items by scale (Field, 2017), we also calculated the average inter-item correlations (a straightforward measure of internal consistency) and found that values were within the recommended range of .15-.50 (Domino \& Domino, 2006).

Discriminant validity was assessed by correlating the BCEs total score with CTQ total score and subscales. As expected, significant negative correlations were found between BCEs and CTQ scores, signifying that more positive childhood experiences were related to fewer experiences of trauma during childhood and vice versa, in accordance with previous studies (Gunay-Oge et al., 2020; Narayam et al., 2018). In fact, positive experiences and strong childhood relationships promote resilience, which plays a key role in overcoming adverse experiences throughout life (Poole, Dobson, \& Pusch 2017; Sege \& Browne, 2017).

The comparison analysis of different variables revealed that married individuals reported more positive childhood experiences than single participants. In fact, positive life events in childhood contribute to the development of positive affect (Park et al., 2004), which may play an important role in the development of relationships with others (Labella, Raby, 
Martin, \& Roisman, 2019). Additionally, participants over 41 years of age reported more positive childhood experiences than younger individuals. However, this may be due to the fact that older participants were mostly married or lived with their partners, rather than being an age-related effect. In addition, participants with higher academic qualifications also reported more positive childhood experiences, a finding that is in line with those of previous studies that point to positive correlations between social and emotional experiences shared with caregivers and other children and adults and academic achievement (e.g., Denham \& Brown, 2010). Participants who were employed, retired, and students also reported more positive childhood experiences than unemployed individuals, concurring with prior studies that showed a relationship between childhood trauma and unemployment in adulthood (Liu et al., 2012). This finding may be related to the fact that adverse childhood experiences have been shown to decrease cognitive ability (Boden, Horwood, \& Fergusson, 2007). Moreover, participants who had more positive childhood experiences reported less trauma and less victimization experiences in adulthood. Results are in line with previous studies showing that vulnerability in childhood tends to persist in adulthood (Sigurdasdottir \& Halldorsdottir, 2012), while positive experiences promote better health and wellbeing in adulthood (Crandall et al., 2019).

The study findings regarding predictive validity showed that higher BCEs scores were negatively correlated with both trauma and victimization experiences in the last three years. However, after accounting for adverse childhood experiences (i.e., the total CTQ scores and subscales), the BCEs scores did not predict trauma or victimization. The total CTQ score, emotional abuse and physical neglect in childhood, and being separated or divorced were significantly correlated with traumatic experiences over the last three years. On the other hand, being younger, total CTQ scores, and emotional abuse were correlated with victimization experiences during the last three years. Thus, even when coexisting alongside positive childhood experiences, negative childhood experiences seem to have a greater impact on 
adversity in adulthood. In fact, previous studies revealed that abuse during childhood may be related to sexual abuse (Ports, Ford, \& Merrick, 2016), intimate partner abuse (Riedl et al., 2019), and other forms of victimization in adulthood (Desir \& Karatekin, 2019).

The cluster analysis results demonstrate how the BCEs can neutralize or compensate for the effects of trauma. This analysis revealed that participants fell into three groups, including those with high BCEs levels and low childhood trauma levels ("High BCEs"), those with low BCEs levels and high childhood trauma levels ("Low BCEs"), and those with moderate BCEs levels and moderate childhood trauma levels ("Moderate BCEs"). The groups differ based upon the average trauma and victimization experience levels over the past three years, with the "High BCEs" cluster revealing the lowest scores for both variables and the "Low BCEs" cluster reporting the highest scores. Furthermore, the "Low BCEs" cluster was comprised of a higher number of divorced or separated and unemployed individuals, with lower levels of educational attainment. On the other hand, individuals in the "High BCEs" group were more likely to be married or live with their partners, in addition to possessing higher literacy skills, on average. Together, these results support the idea that high levels of childhood adversity may comprise a risk factor that could impact an individual's adjustment in adulthood (e.g., Beilharz et al., 2019; Nikulina \& Widom, 2013), while higher BCEs scores seem to have a protective effect that contributes to better functioning in adulthood (e.g., Crandall et al., 2019; Poole et al., 2017; Sege et al., 2017).

This study possesses some limitations that may influence its results. The sample lacks heterogeneity, since it is mainly composed of female participants. It is also important to mention that, following online sample recruitment, it was not possible to control the environment in which participants responded to the research protocol. Since the study measurement instruments are self-reported, social desirability bias may have influenced participants' responses. Reflecting upon the aforementioned limitations, the authors 
recommend that future studies utilize more homogeneous samples, especially concerning gender. Finally, our sample is not representative of the entire Portuguese population, which prohibits the generalization of its results.

Despite its limitations, this study is of great relevance, as it is the first adaptation of the Portuguese version of the BCEs. The BCEs revealed appropriate psychometric properties and is a valid and reliable tool for use in the Portuguese context. Moreover, it is a brief instrument with a quick response time, which makes it even more attractive. As there is little prior research regarding this subject, the current study fills an important gap in the literature by offering an adequate tool to assess positive life experiences.

\section{References}

Aaron, E., Criniti, S., Bonacquisti, A., \& Geller, P. (2013). Providing sensitive care for adult HIV-infected women with a history of childhood sexual abuse. The Journal of Association of Nurses in AIDS Cares, 24(4), 355-367. http://dx.doi.org/10.1016/j.jana.2013.03.004

Assche, L. V., Vem, L. V., Vandenbulcke, M., \& Luyten, P. (2020). Ghosts from the past? The association between childhood interpersonal trauma, attachment and anxiety, and depression in late life. Aging \& Mental Health, 24(6), 898-905. https://doi.org/10.1080/13607863.2019.1571017

Azevedo, V. M. F. S. (2016). Experiências de vida e sintomatologia psicopatológica (re)contadas na vida adulta: O que se conta? O que vale o que se conta? E o que conta para se contar? [Life experiences and psychopathological symptoms (re)told in adult life: What is counted? What is worth what is counted? And what counts to be counted?] [Unpublished doctoral dissertation]. School of Psychology, University of Minho. 
Beilharz, J. E., Paterson, M., Fatt, S., Wilson, C., Burton, A., Cvejic, E., Lloyd, A., \& Vollmer-Conna, U. (2019). The impact of childhood trauma on psychosocial functioning and physical health in a non-clinical community sample of young adults. Australian \& New Zealand Journal of Psychiatry, 00(0), 1-10. https://doi.org/10.1177/0004867419881206

Bernstein, D. P., Stein, J.A., Newcomb, M. D., Walker, E., Pogge, D., Ahluvalia, T., Stokes, J., Handelsman, L., Medrano, M., Desmond, D., \& Zule, W. (2003). Development and validation of a brief screening version of the Childhood Trauma Questionnaire. Child Abuse \& Neglect, 27(2), 169-190. https://doi.org/10.1016/S0145-2134(02)00541-0

Bethell, C., Jones, J., Gombojav, N., Linkenbach, J., \& Sege, R. (2019). Positive childhood experiences and adult mental and relational health in a statewide sample: Association across adverse childhood experiences levels. JAMA Pediatrics, 173(11), 1-10. https://doi:10.1001/jamapediatrics.2019.3007

Boden, J.M., Horwood, L.J., Fergusson, D.M. (2007). Exposure to childhood sexual and physical abuse and subsequent educational achievement outcomes. Child Abuse and Neglect, 31(10), 1101-1114. https://doi.org/10.1016/j.chiabu.2007.03.022

Braga, T., Cunha, O., Maia, A. (2018). The enduring effect of maltreatment on antisocial behavior: A meta-analysis of longitudinal studies. Aggression and Violent Behavior. https://doi.org/10.1016/j.avb2018.04.003

Bussey, M., \& Wise, J. (Eds.) (2007). Trauma transformed: An empowerment response. New York: Columbia University Press.

Caldera, Y, \& Hart, S. (2004). Exposure to child care, parenting style, and attachment security. Infant and Child Development, 13, 21-33. https://doi.org/10.1002/icd.329

Cicchetti, D., \& Toth, S.L., 2005. Child maltreatment. Annual Review of Clinical Psychology, 1, 409-438. https://doi.org/10.1146/annurev.clinpsy.1.102803.144029 
Cicchetti, D., \& Toth, S. L. (2009). The past achievements and future promises of developmental psychopathology: The coming of age of a discipline. The Journal of Child Psychology and Psychiatry, 50, 16-25. http://dx.doi.org/10.1111/j.14697610.2008.01979.x.

Crandall, A., Miller, J. R., Cheung, A., Novilla, L. K., Glade, R., Novilla, M. L. B., Magnusson, B. M., Leavitt, B. L., Barnes, M. D., Hanson, C. L. (2019). ACEs and counter-ACEs: How positive and negative childhood experiences influence adult health. Child Abuse \& Neglect, 96, 1-9. https://doi.org/10.1016/j.chiabu.2019.104089

Cronbach, L. J. (1951). Coefficient alpha and the internal structure of tests. Psychometrika, $16,297-334$.

Denham, S. A., \& Brown, C. (2010). "Plays nice with others": Social-emotional learning and academic success. Early Education and Development, 21(5), 652-680. http://dx.doi.org/10.1080/10409289.2010.497450

Desir, M. P., \& Karatekin, C. (2019). Characteristics of disclosing childhood victimization and risk of revictimization in young adulthood. Journal of Interpersonal Violence 00(0), 1-27. https://doi.org/10.1177/0886260519889932

Dias, A., Sales, L., Carvalho, A., Castro-Vale, I., Kleber, R., \& Cardoso, R. M. (2013). Estudo de propriedades psicométricas do Questionário de Trauma de Infância - Versão breve numa amostra portuguesa não clínica. [Study of psychometric properties of the Childhood Trauma Questionnaire - Short version in a non-clinical Portuguese sample]. Laboratório de Psicologia, 11(2), 103-120. https://doi.org/10.14417/lp.11.2.713

Domino, G., \& Domino, M. (2006). Psychological testing: An introduction (2nd ed.). New York: Cambridge University Press. 
Eizirik, M., Schestatsky, S., Knijnik, L., Terra, L., \& Ceitlin, L. (2006). Contratransferência e trauma psíquico. [Contra-transference and psychological trauma]. Revista de Psiquiatria, 28(3), 314-320. https://doi.org/10.1590/S0101-81082006000300010

Field, A. (2017). Discovering statistics using SPSS statistics $\left(5^{\text {th }}\right.$ Ed.). London: Sage.

Gable, S. L., \& Haidt, J. (2005). What (and why) is positive psychology? Review of General Psychology, 9(2), 103-110. https://doi.org/10.1037/1089-2680.9.2.103

Gunay-Oge, R., Pehlivan, F. Z., \& Isikli, S. (2020). Validity and reliability of the Benevolent Childhood Experiences (BCEs) Scale in Turkish. The Journal of Psychiatry and Neurological Sciences, 33, 146-154. 10.14744/DAJPNS.2020.00074

Hair, J., Anderson, R., Tatham, R. and Black, W. (1998). Multivariate data analysis (5th Ed.). New Jersey: Prentice Hall.

Hillis, S. D., Anda, R. F., Dube, S. R., Felitti, V. J., Marchbanks, P. A., Macaluso, M., \& Marks, J. S. (2010). The protective effect of family strengths in childhood against adolescent pregnancy and its long-term psychosocial consequences. The Permanent Journal, 14(3), 18-27. 10.7812/tpp/10-028

Karatzias, T., Shevlin, M., Fyvie, C., Grandison, G., Garozi , M., Latham, E., ... \& Hyland, P. (2020). Adverse and benevolent childhood experiences in Posttraumatic Stress Disorder (PTSD) and Complex PTSD (CPTSD): implications for trauma-focused therapies. European Journal of Psychotraumatology, 11(1), 1793599. https://doi.org/10.1080/20008198.2020.1793599

Kosterman, R., Mason, A., Haggerty, K., Hawkins, D., Spoth, R., \& Redmond, C. (2011). Positive childhood experiences and positive adult functioning: Prosocial continuity and the role of adolescent substance use. Journal of Adolescent Health, 49, 180-186. https://dx.doi.org/10.1016/j.jadohealth.2010.11.244 
Kosterman, R., Hawkins, D., Abbott, R., Hill, K., Herrenkohl, T., \& Catalano, R. (2005). Measures of positive adult behavior and their relationship to crime and substance abuse. Prevention Science, 6(1), 21-33. https://doi.org/10.1007/s11121-005-1250-0

Labella, M., Raby, L., Martin, J., \& Roisman, G. I. (2019). Romantic functioning mediates prospective associations between childhood abuse and neglect and parenting outcomes in adulthood. Development and Psychopathology, 31, 95-111. http://dx.doi.org/10.1017/S095457941800158X

Liu, Y., Croft, J. B., Chapman, D. P., Perry, G. S., Greenlund, K. J., Zhao, G., \& Edwards, V. J. (2013). Relationship between adverse childhood experiences and unemployment among adults from five US states. Social Psychiatry and Psychiatric Epidemiology, 48, 357-369. https://doi.org/10.1007/s00127-012-0554-1

Luthar, S. S., Crossman, E. J., \& Small, P. J. (2015). Resilience and adversity. In R. M. Lerner, \& M. E. Lamb (Eds.), Handbook of child psychology and developmental science: Vol. III (7th ed., pp. 247-286). New York: Wiley.

Marôco, J. (2014). Análise de equações estruturais. Fundamentos teóricos. Software \& aplicações. [Analysis of structural equations. Theoretical foundations. Software \& applications]. Pero Pinheiro: Report Number.

Marques-Pinto, A., Oliveira, S., Santos, A., Camacho, C., Silva, D. P., Pereira, M. S. (2019). Does our age affect the way we live? A study on savoring strategies across the life span. Journal of Happiness Studies. https://doi.org/10.1007/s10902-019-00136-4

Masten, A. S. (2014). Ordinary magic: Resilience in development. New York: Guilford. Masten, A. S., \& Cicchetti, D. (2010). Developmental cascades. Development and Psychopathology, 22(3), 491-495. https://doi.org/10.1017/S0954579410000222 
Masten, A. S., \& Cicchetti, D. (2016). Resilience in development: Progress and transformation. In D. Cicchetti (Ed.), Developmental psychopathology: Risk, resilience, and intervention (p. 271-333). John Wiley \& Sons.

Merrick, J. S., Narayan, A. J., DePasquale, C. E., \& Masten, A. S. (2019). Benevolent childhood experiences (BCEs) in homeless parents: A validation and replication study. Journal of Family Psychology, 33(4), 493-498. https://doi.org/10.1037/fam0000521

Merrick, J. S., Narayan, A. J., Atzl, V. M., Harris, W. W., Liberman, A. F. (2020) Type versus timing of adverse and benevolent childhood experiences for pregnant women's psychological and reproductive health. Children and Youth Services Review, 114, 1-11. https://doi.org/10.1016/j.childyouth.2020.105056

Narayan, A. J., Rivera, L. M., Bernstein, R. E., Harris, W. W., \& Lieberman, A. F. (2018). Positive childhood experiences predict less psychopathology and stress in pregnant women with childhood adversity: A pilot study of the benevolent childhood experiences (BCEs) scale. Child And Abuse Neglect, 1-12. https://dx.doi.org/10.10.16/j.chiabu.2017.09.022

Nikulina, V., \& Widom, C. S. (2013). Child maltreatment and executive functioning in middle adulthood: A prospective examination. Neuropsychology, 27(4), 417-427. https://doi.org/10.1037/a0032811

Park, N. (2004). The role of subjective well-being in positive youth development. The ANNALS of the American Academy of Political and Social Science, 591(1), 2539. https://doi.org/10.1177/0002716203260078

Peres, J., Mercante, J., \& Nasello, A. (2005). Promovendo resiliência em vítimas de trauma psicológico. [Promoting resilience in victims of psychological trauma]. Revista de Psiquiatria, 27(2), 131-138. https://doi.org/10.1590/S0101-81082005000200003 
Poole, J. C., Dobson, K. S., \& Pusch, D. (2017). Childhood adversity and adult depression: The protective role of psychological resilience. Child Abuse and Neglect, 64, 89-100. https://doi.org/10.1016/j.chiabu.2016.12.012

Ports, K. A., Ford, D. C., Merrick, M. T. (2016). Adverse childhood experiences and sexual victimization in adulthood. Child abuse and neglect, 51, 313-322. https://doi.org/10.1016/j.chiabu.2015.08.017

Riedl, D., Beck, T., Exenberger, S., Daniels, J., Dejaco, D., Unterberger, I., \& Lampe, A. (2019). Violence from childhood to adulthood: The influence of child victimization and domestic violence on physical health in later life. Journal of Psychosomatic Research, 116, 68-74. https://doi.org/10.1016/j.jpsychores.2018.11.019

Sege, R. D., \& Browne, C. H. (2017). Responding to ACEs with HOPE: Health outcomes from positive experiences. Academic Pediatrics, 17(7). S79-S85. https://doi.org/10.1016/j.acap.2017.03.007

Sigurdardottir, S., Halldorsdottir, S. and Bender, S.S. (2012), Deep and almost unbearable suffering: consequences of childhood sexual abuse for men's health and well-being. Scandinavian Journal of Caring Sciences, 26, 688-697. https://doi.org/10.1111/j.14716712.2012.00981.x

Taber, K. S. (2018). The use of Cronbach's alpha when developing and reporting research instruments in science education. Research in Science Education, 48, 1273-1296. https://doi.org/10.1007/s11165-016-9602-2

Toth, S. L., \& Cicchetti, D. (2013). A developmental psychopathology perspective on child maltreatment. Child Maltreatment, 18(3), 135139. https://doi.org/10.1177/1077559513500380 
van Griethuijsen, R.A.L.F., van Eijck, M.W., Haste, H. (2015).Global Patterns in Students' V iews of Science and Interest in Science. Research in Science Education, 45, 581603. https://doi.org/10.1007/s11165-014-9438-6

Vet, H. C. W., Mokkink, L. B., Mosmuller, D. G., \& Terwee, C. B. (2017). Spearman-Brown prophecy formula and Cronbach's alpha: different faces of reliability and opportunities for new applications. Journal of Clinical Epidemiology, 85, 45-49. http://dx.doi.org/10.1016/j.jclinepi.2017.01.013

Wilkins, N., Tsao, B., Hertz, M., Davis, R., Klevens, J. (2014). Connecting the Dots: An Overview of the Links Among Multiple Forms of Violence. Atlanta, GA: National Center for Injury Prevention and Control, Centers for Disease Control and Prevention Oakland, CA: Prevention Institute

World Medical Association. (2013). World medical association declaration of Helsinki: Ethical principles for medical research involving human subjects. JAMA, 310(20), 21912194. http://dx.doi.org/10.1001/jama.2013.281053

Wright, M. O., Masten, A. S., \& Narayan, A. J. (2013). Resilience processes in development: Four waves of research on positive adaptation in the context of adversity. In S. Goldstein, \& R. B. Brooks (Eds.). Handbook of resilience in children (2nd ed., pp. 15-37). New York: Kluwer Academic/Plenum.

Yamaoka, Y., \& Bard, D. E. (2019). Positive matters in the face of early adversity. American Journal of Preventive Medicine, 56(4). http://dx.doi.org/10.1016/j.amepre.2018.11.018

Zautra, A. J., \& Reich, J. W. (1981). Positive events and quality of life. Evaluation and Program Planning, 4(3-4), 355-361. https://doi.org/10.1016/0149-7189(81)90034-3 


\section{Table 1}

BCEs items and frequencies

When you were growing up, during your first 18 years of life...

\begin{tabular}{lll}
\hline Item Question & $(n=1886)$
\end{tabular}

$1 \quad$ Did you have at least one caregiver with whom you felt safe? $\quad 96.5 \%$

2 Did you have at least one good friend? $\quad 96.8 \%$

3 Did you have beliefs that gave you comfort? $\quad 84.3 \%$

$4 \quad$ Did you like school? $\quad 89.1 \%$

$5 \quad$ Did you have at least one teacher who cared about you? $\quad 92.2 \%$

$6 \quad$ Did you have good neighbors? $\quad 87.3 \%$

Was there an adult (not a parent/caregiver or the person from \#1) who

$86.5 \%$

could provide you with support or advice?

8 Did you have opportunities to have a good time? $94.4 \%$

9 Did you like yourself or feel comfortable with yourself? $\quad 74.1 \%$

Did you have a predictable home routine, like regular meals and a 10 regular bedtime? 
Table 2

Correlations between the BCEs scale and CTQ scale $(n=1886)$

\begin{tabular}{|c|c|c|c|c|c|c|c|c|}
\hline & & 1 & 2 & 3 & 4 & 5 & 6 & 7 \\
\hline 1. & BCEs total score & 1 & $-.567 * *$ & $-.54 * *$ & $-.557 * *$ & $-.20 * *$ & $-.35 * *$ & $-.41 * *$ \\
\hline 2. & CTQ total score & & 1 & $.85^{* *}$ & $.81 * *$ & $.50 * *$ & $.72 * *$ & $.72 * *$ \\
\hline 3. & CTQ emotional abuse & & & 1 & $.67 * *$ & $.33 * *$ & $.55 * *$ & $.46^{* *}$ \\
\hline 4. & CTQ emotional neglect & & & & 1 & $.25 * *$ & $.44 * * *$ & $.60 * *$ \\
\hline 5. & CTQ sexual abuse & & & & & 1 & $.26 * *$ & $.24 * *$ \\
\hline 6. & CTQ physical abuse & & & & & & 1 & $.44 * *$ \\
\hline 7. & CTQ physical neglect & & & & & & & 1 \\
\hline
\end{tabular}

Note. ${ }^{*} p<.05, * * p<.01$ 


\section{Table 3}

Means, Standard Deviations, and One-Way Analyses of BCEs $(n=1886)$

\begin{tabular}{|c|c|c|c|c|}
\hline \multirow[t]{2}{*}{ Variables } & \multicolumn{2}{|c|}{ BCEs } & \multirow[t]{2}{*}{$F(1.1884)$} & \multirow[t]{2}{*}{$\eta^{2}$} \\
\hline & $M$ & $D P$ & & \\
\hline Trauma & .86 & .17 & 38.33 & $<.01$ \\
\hline No trauma & .91 & .13 & & \\
\hline Victimization & .84 & .18 & 47.53 & $<.01$ \\
\hline No victimization & .90 & .14 & & \\
\hline Male & .89 & 14 & .64 & $<.01$ \\
\hline Female & .89 & .15 & & \\
\hline Age $18-40$ & .88 & .15 & 4.10 & $<.01$ \\
\hline Age +40 & .90 & .15 & & \\
\hline Until $9^{\text {th }}$ grade & .83 & .19 & 13.18 & $<.01$ \\
\hline Until $12^{\text {th }}$ grade & .87 & .16 & & \\
\hline High School & .90 & .14 & & \\
\hline Unemployed & .82 & .19 & 7.21 & $<.01$ \\
\hline Employed & .90 & .14 & & \\
\hline Retired & .89 & .15 & & \\
\hline
\end{tabular}




\begin{tabular}{lcccc} 
Student & .87 & .16 & \\
Other & .86 & .15 & & \\
\hline Single & .88 & .15 & 3.95 & $<.01$ \\
Married/Cohabitation & .90 & .14 & & \\
Separated/Divorced & .87 & .17 & \\
Widower & .87 & .17 &
\end{tabular}

\section{Table 4}

Binary Logistics Regressions for Trauma in the last three years and Victimization in the last three years (Total BCE and Total CTQ) $(n=1886)$

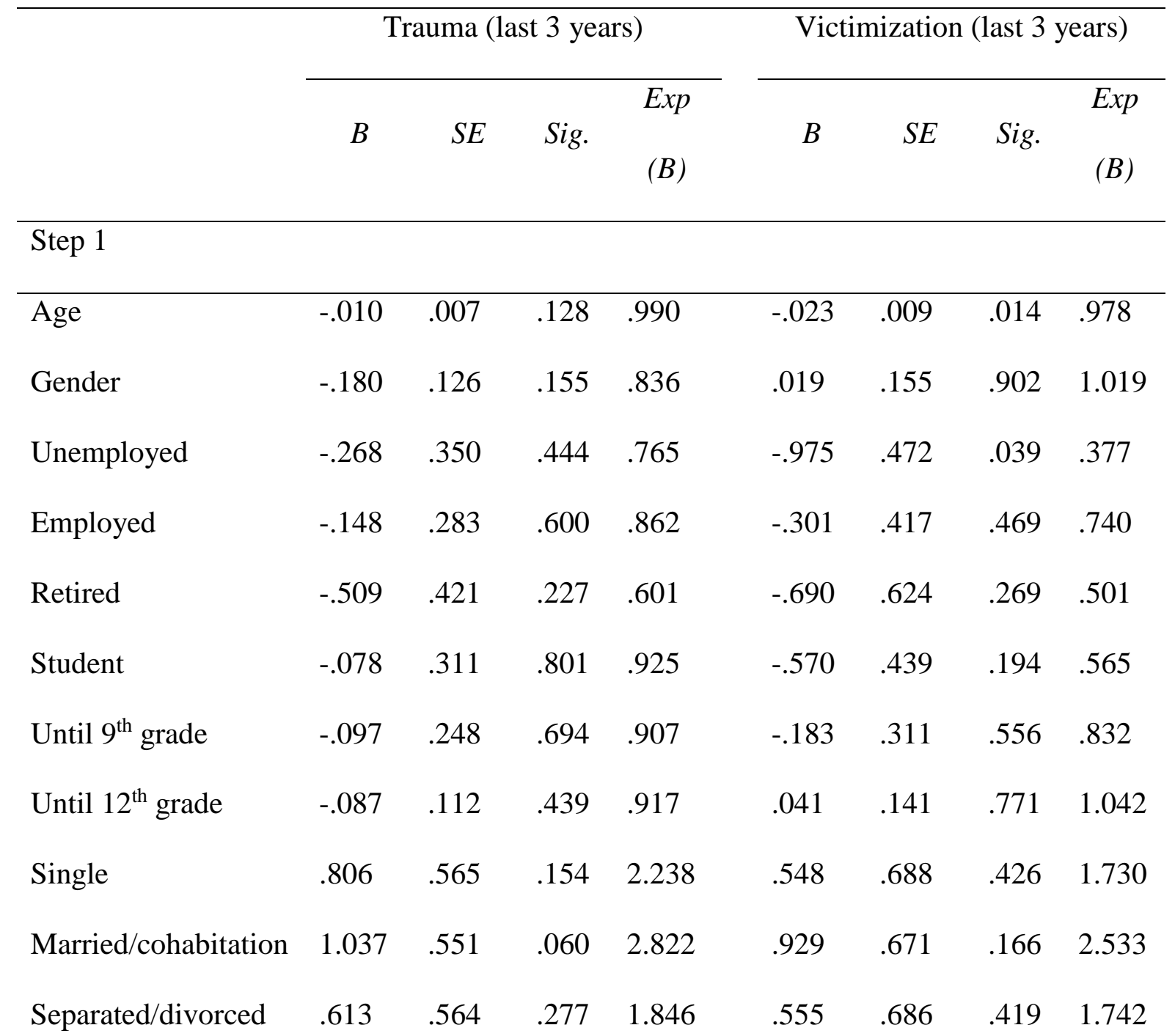


Constant

Step 2

\begin{tabular}{|c|c|c|c|c|c|c|c|c|}
\hline Age & -.010 & .007 & .144 & .990 & -.022 & .009 & .017 & .978 \\
\hline Gender & -.159 & .127 & .210 & .853 & .050 & .156 & .751 & 1.051 \\
\hline Unemployed & -.226 & .354 & .524 & .798 & -.925 & .476 & .052 & .396 \\
\hline Employed & -.208 & .286 & .467 & .812 & -.376 & .420 & .370 & .687 \\
\hline Retired & -.564 & .425 & .184 & .569 & -.739 & .629 & .240 & .477 \\
\hline Student & -.115 & .314 & .714 & .891 & -.623 & .442 & .159 & .536 \\
\hline Until $9^{\text {th }}$ grade & .030 & .253 & .904 & 1.031 & -.020 & .316 & .950 & .981 \\
\hline Until $12^{\text {th }}$ grade & -.056 & .113 & .620 & .945 & .090 & .143 & .526 & 1.095 \\
\hline Single & .809 & .572 & .157 & 2.246 & .522 & .696 & .453 & 1.686 \\
\hline Married/cohabitation & 1.011 & .558 & .070 & 2.749 & .874 & .681 & 199 & 2.397 \\
\hline Separated/divorced & .615 & .570 & .281 & 1.849 & .529 & .695 & .447 & 1.696 \\
\hline BCE Total & -1.587 & .337 & .000 & .205 & -1.951 & .382 & .000 & .142 \\
\hline Constant & .703 & 1.459 & .630 & 2.020 & 1.832 & 1.907 & .337 & 6.245 \\
\hline \multicolumn{9}{|l|}{ Step 3} \\
\hline Age & -.012 & .007 & .093 & .988 & -.025 & .009 & .008 & .975 \\
\hline Gender & -.143 & .128 & .264 & .867 & .075 & .158 & .632 & 1.078 \\
\hline Unemployed & -.190 & .357 & .593 & .827 & -.866 & .479 & .070 & .421 \\
\hline Employed & -.228 & .287 & .427 & .796 & -.357 & .420 & .396 & .700 \\
\hline Retired & -.622 & .429 & .147 & .537 & -.765 & .634 & .228 & .465 \\
\hline Student & -.200 & .316 & .527 & .819 & -.693 & .444 & .119 & .500 \\
\hline Until $9^{\text {th }}$ grade & .133 & .259 & .607 & 1.142 & .120 & .325 & .713 & 1.127 \\
\hline Until $12^{\text {th }}$ grade & -.020 & .114 & .861 & .980 & .129 & .144 & .370 & 1.138 \\
\hline Single & .879 & .578 & .128 & 2.409 & .584 & .712 & .412 & 1.793 \\
\hline
\end{tabular}




\begin{tabular}{lllllllll} 
Married/cohabitation & 1.091 & .563 & .053 & 2.978 & .940 & .696 & .177 & 2.559 \\
Separated/divorced & .695 & .576 & .228 & 2.003 & .601 & .710 & .397 & 1.824 \\
BCE Total & -.402 & .404 & .320 & .669 & -.633 & .469 & .177 & .531 \\
CTQ Total & 1.075 & .202 & .000 & 2.930 & 1.144 & .224 & .000 & 3.141 \\
Constant & -2.277 & 1.568 & .147 & .103 & -1.473 & 2.041 & .471 & .229 \\
& & & & & & & & \\
\hline
\end{tabular}

\section{Table 5}

Binary Logistics Regressions for Trauma in the last three years and Victimization in the last three years (Total BCE and CTQ subscales) $(n=1886)$

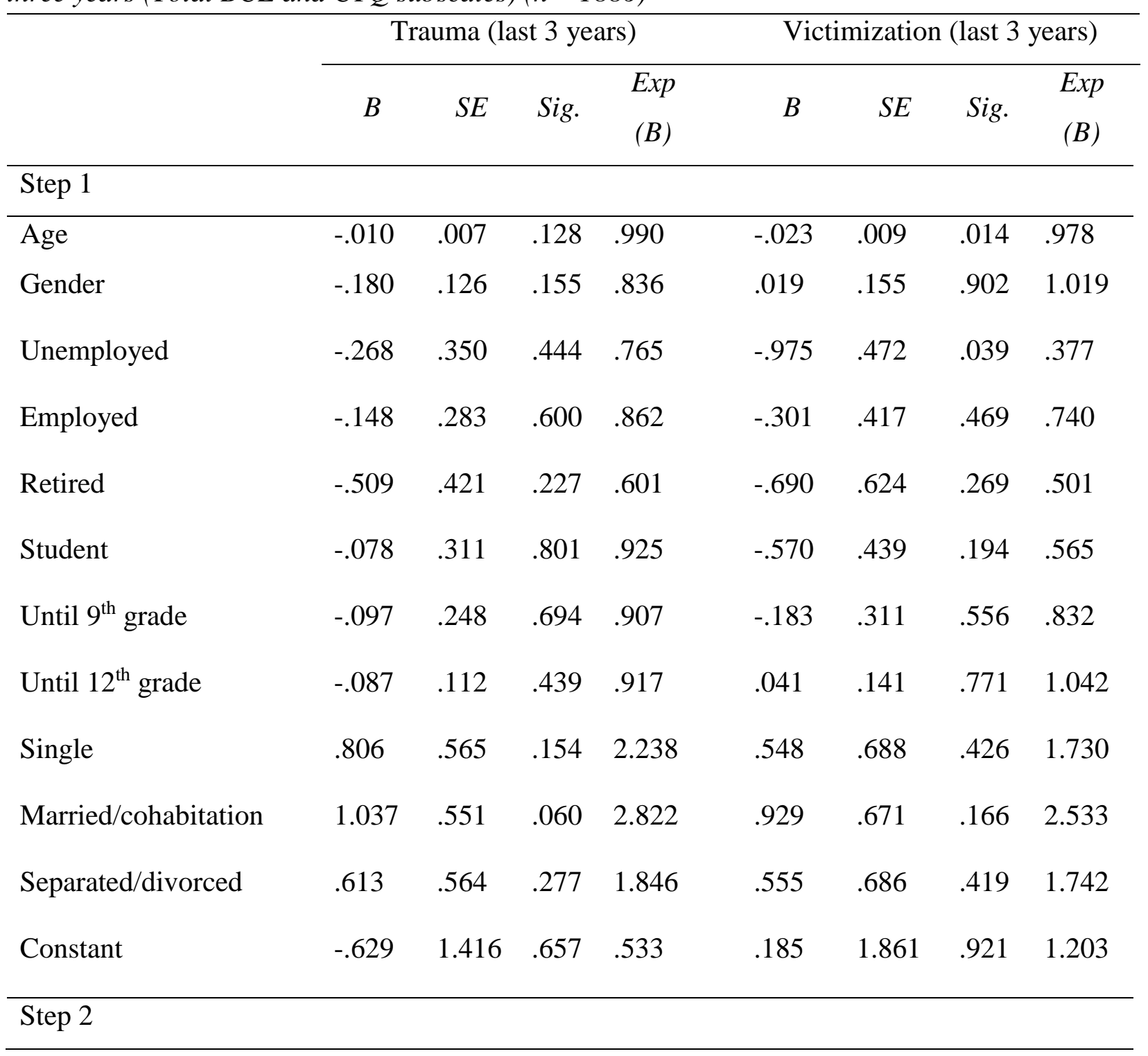




\begin{tabular}{|c|c|c|c|c|c|c|c|c|}
\hline Age & -.010 & .007 & .144 & .990 & -.022 & .009 & .017 & .978 \\
\hline Gender & -.159 & .127 & .210 & .853 & .050 & .156 & .751 & 1.051 \\
\hline Unemployed & -.226 & .354 & .524 & .798 & -.925 & .476 & .052 & .396 \\
\hline Employed & -.208 & .286 & .467 & .812 & -.376 & .420 & .370 & .687 \\
\hline Retired & -.564 & .425 & .184 & .569 & -.739 & .629 & .240 & .477 \\
\hline Student & -.115 & .314 & .714 & .891 & -.623 & .442 & .159 & .536 \\
\hline Until $9^{\text {th }}$ grade & .030 & .253 & .904 & 1.031 & -.020 & .316 & .950 & .981 \\
\hline Until $12^{\text {th }}$ grade & -.056 & .113 & .620 & .945 & .090 & .143 & .526 & 1.095 \\
\hline Single & .809 & .572 & .157 & 2.246 & .522 & .696 & .453 & 1.686 \\
\hline Married/cohabitation & 1.011 & .558 & .070 & 2.749 & .874 & .681 & .199 & 2.397 \\
\hline Separated/divorced & .615 & .570 & .281 & 1.849 & .529 & .695 & .447 & 1.696 \\
\hline BCE Total & -1.587 & .337 & .000 & .205 & -1.951 & .382 & .000 & .142 \\
\hline Constant & .703 & 1.459 & .630 & 2.020 & 1.832 & 1.907 & .337 & 6.245 \\
\hline \multicolumn{9}{|l|}{ Step 3} \\
\hline Age & -.010 & .007 & .162 & .990 & -.023 & .010 & .018 & .978 \\
\hline Gender & -.124 & .130 & .342 & .884 & .112 & .161 & .487 & 1.118 \\
\hline Unemployed & -.156 & .359 & .664 & .856 & -.822 & .481 & .088 & .440 \\
\hline Employed & -.199 & .289 & .491 & .820 & -.332 & .423 & .433 & .718 \\
\hline Retired & -.588 & .432 & .174 & .556 & -.735 & .639 & .250 & .479 \\
\hline Student & -.160 & .318 & .616 & .853 & -.656 & .448 & .143 & .519 \\
\hline Until $9^{\text {th }}$ grade & .080 & .261 & .759 & 1.084 & .040 & .329 & .904 & 1.041 \\
\hline Until $12^{\text {th }}$ grade & -.037 & .115 & .748 & .964 & .114 & .145 & .432 & 1.121 \\
\hline Single & .185 & .179 & .302 & 1.203 & -.022 & .230 & .923 & .978 \\
\hline Married/cohabitation & .912 & .579 & .115 & 2.489 & .642 & .711 & .367 & 1.900 \\
\hline Separated/divorced & .401 & .173 & .021 & 1.494 & .347 & .235 & .140 & 1.415 \\
\hline
\end{tabular}




\begin{tabular}{lcccccccc} 
BCE Total & -.012 & .042 & .768 & .988 & -.032 & .049 & .514 & .968 \\
CTQ Emotional Abuse & .091 & .022 & .000 & 1.096 & .102 & .025 & .000 & 1.107 \\
CTQ Emotional Neglect & -.004 & .018 & .807 & .996 & -.010 & .022 & .657 & .990 \\
CTQ Sexual Abuse & -.003 & .031 & .928 & .997 & .020 & .035 & .574 & 1.020 \\
CTQ Physical Abuse & .006 & .032 & .839 & 1.007 & -.008 & .035 & .820 & .992 \\
CTQ Physical Neglect & .057 & .029 & .048 & 1.058 & .066 & .034 & .054 & 1.068 \\
Constant & -.541 & 1.143 & .636 & .582 & .017 & 1.575 & .922 & 1.017 \\
\hline
\end{tabular}




\section{Table 6}

Descriptive Statistics for the Clusters $(n=1886)$

Cluster $\quad$ Cluster 1 Low BCEs $(n=108) \quad$ Cluster 2 High BCEs $(n=1308) \quad$ Cluster 3 Moderated BCEs $(n=470) \quad F$ - $\square 2 \quad p$

Indicadors

\begin{tabular}{|c|c|c|c|c|c|}
\hline BCES & $.63(.22)$ & $.95(.09)$ & $.79(.17)$ & 529.713 & $<.001$ \\
\hline CTQ & $2.67(.31)$ & $1.51(.11)$ & $1.93(.16)$ & 4533.106 & $<.001$ \\
\hline Age & $38.69(11.94)$ & $36.00(13.83)$ & $36.84(13.52)$ & 2.333 & .097 \\
\hline \multirow[t]{2}{*}{ Gender } & Male $=18.5 \%(n=20)$ & Male $=22.6 \%(n=296)$ & Male $=20.2 \%(n=95)$ & 1.906 & .386 \\
\hline & Female $=81.5 \%(n=88)$ & Female $=77.4 \%(n=1012)$ & Female $=79.8 \%(n=375)$ & & \\
\hline Educational & Until $9^{\text {th }}$ grade $=16.3 \%(n=16)$ & Until $9^{\text {th }}$ grade $=4.2 \%(n=52)$ & Until $9^{\text {th }}$ grade $=5.7 \%(n=25)$ & 16.581 & $<.001$ \\
\hline \multirow[t]{2}{*}{ level } & Until $12^{\text {th }}$ grade $=31.6 \%(n=31)$ & Until $12^{\text {th }}$ grade $=30.9 \%(n=384)$ & Until $12^{\text {th }}$ grade $=37.1 \%(n=162)$ & & \\
\hline & High school $=52 \%(n=51)$ & High school $=64.9 \%(n=806)$ & High school $=57.2 \%(n=250)$ & & \\
\hline \multirow[t]{4}{*}{ Marital status } & Single $=35.2 \%(n=38)$ & Single $=47.8 \%(n=625)$ & Single $=47 \%(n=221)$ & 13.901 & .031 \\
\hline & Married $/$ cohabitation $=48.1 \%(n=$ & Married $/$ cohabitation $=44.5 \%(n=582)$ & Married/cohabitation $=44.3 \%(n=208)$ & & \\
\hline & 52) & Separated/divorced $=7.1 \%(n=93)$ & Separated/divorced $=7.7 \%(n=36)$ & & \\
\hline & Separated/divorced $=14.8 \%(n=16)$ & Widower $=0.6 \%(n=8)$ & Widower $=0.8 \%(n=5)$ & & \\
\hline
\end{tabular}


Widower $=1.9 \%(n=2)$

$\begin{array}{llll}\text { Professional } & \text { Unemployed }=10.2 \%(n=11) & \text { Unemployed }=3.7 \%(n=48) & \text { Unemployed }=8.7 \%(n=41) \\ \text { status } & \text { Employed }=70.4 \%(n=76) & \text { Employed }=63.9 \%(n=836) & \text { Employed }=59.8 \%(n=281) \\ & \text { Retired }=4.6 \%(n=5) & \text { Retired }=4.3 \%(n=56) & \text { Retired }=4.3 \%(n=20) \\ & \text { Student }=11.1 \%(n=12) & \text { Student }=25.2 \%(n=329) & \text { Student }=21.3 \%(n=100) \\ & & 35.8 \%(n=468) & 54 \%(n=254) \\ \text { Trauma (last } & 61.1 \%(n=66) & & \\ \text { 3 years) } & & 15.1 \%(n=19) & 29.1 \%(n=137)\end{array}$

